\title{
W. Donald Wilson, La structure de dédoublement. Objectivité et mythe dans Les Thibault" de Roger Martin du Gard
}

\section{Emanuele Kanceff}

\section{(2) OpenEdition \\ Journals}

\section{Edizione digitale}

URL: http://journals.openedition.org/studifrancesi/28001

DOI: 10.4000/studifrancesi.28001

ISSN: 2421-5856

\section{Editore}

Rosenberg \& Sellier

\section{Edizione cartacea}

Data di pubblicazione: 31 décembre 2006

Paginazione: 636

ISSN: 0039-2944

\section{Notizia bibliografica digitale}

Emanuele Kanceff, «W. Donald Wilson, La structure de dédoublement. Objectivité et mythe dans Les Thibault" de Roger Martin du Gard ", Studi Francesi [Online], 150 (L | III) | 2006, online dal 30 novembre 2015, consultato il 08 novembre 2020. URL : http://journals.openedition.org/studifrancesi/28001 ; DOI : https://doi.org/10.4000/studifrancesi.28001

\section{Questo documento è stato generato automaticamente il 8 novembre 2020}

\section{cc) $($ ) $\ominus$}

Studi Francesi è distribuita con Licenza Creative Commons Attribuzione - Non commerciale - Non opere derivate 4.0 Internazionale. 


\title{
W. Donald Wilson, La structure de dédoublement. Objectivité et mythe dans Les Thibault" de Roger Martin du Gard
}

\author{
Emanuele Kanceff
}

\section{NOTIZIA}

W. DONALD WILSON, La structure de dédoublement. Objectivité et mythe dans Les Thibault" de Roger Martin du Gard, Birmingham (Alabama), Summa Publications, 1997, pp. 238.

Segnaliamo con grande ritardo questo interessante studio sui Thibault di Roger Martin du Gard, che, sotto apparenza di favola mitologica, sul filo di capitoli con titoli come “Cronos", “Télémaque”, “Déméter", “Aphrodite”, “Narcisse”, “Les Jumeaux”, vuole illustrare il doppio cammino della scrittura del noto romanziere e studiare quindi, nel loro storico divenire, i misteriosi rapporti tra oggettività e mito, ai fini di valutare appieno il lato edipeo dell'opera, ma anche per mostrare come l'ottica realista si carichi di un significato secondo, di una visione metaforica dei personaggi e del mondo. 